\title{
Advances in New Targets for Differentiation Therapy of Acute Myeloid Leukemia
}

\author{
Jingfang Yao, Mengjie Zhao, Jiangyun Wang* and Liuya Wei
}

\author{
School of Pharmacy, Weifang Medical University, Weifang, 261053, China
}

\begin{abstract}
Acute myeloid leukemia (AML) is a clinical and genetic heterogeneous disease with a poor prognosis. Recent advances in genomics and molecular biology have immensely improved the understanding of disease. The advantages of syndrome differentiation and treatment are strong selectivity, good curative effect and lesser side effects. In recent years, according to the molecular mechanism of acute myeloid leukemia, many new therapeutic targets have been found. New targets of differentiation therapy in recent years, such as cell cyclin-dependent kinase (CDK2), isocitrate dehydrogenase (IDH1, IDH2), Homeobox genes (HoxA9), Dihy-droorotate dehydrogenase (DHODH) and some others, are reviewed in this article.
\end{abstract}

Keywords: Acute myeloid leukemia, differentiation therapy, cell cyclin-dependent kinase, homeobox genes.

\section{INTRODUCTION}

Acute myeloid leukemia (AML), the most common type of adult leukemia, is a malignant tumor with the minimum viability of all leukemia. It is a myeloid cancer of sanguine cells characterized by blockage of cell differentiation [1-3]. Three to four out of 100,000 people suffer from AML, with an average age of 67 years, and the 5-year survival rate is $20 \%$ [4]. Although remarkable march has been made in the treatment of various types of cancer in recent years, AML is still a fatal disease, and its survival rate falls behind that of other blood cancers 5]. Being a genetic heterogeneous disease, it is caused by the build-up of acquired character gene changes in hematopoietic progenitor cells, which alter the mechanism of self-renewal, proliferation and differentiation of cells [6].

In recent years, the new targeted proteins and genes of differentiation therapy for AML have received wide attention [7]. Among these, CDK2 is a member of CDKs playing a key role in proliferation and differentiation of AML; DHODH is a key enzyme which induces terminal differentiation of leukemic cells whereas FLT3 is one of the most frequently mutated genes in AML. Other new targets such as IDH1/2, HoxA9 and PU.1 are also summarized in this review.

\section{NEW TARGETED PROTEINS AND GENES OF DIFFERENTIATION THERAPY}

\subsection{Cyclin Dependent Kinase 2 (CDK2)}

Lack of differentiation is a marked feature of AML, so overcoming the differentiation retardant is an

\footnotetext{
*Address correspondence to these authors at the School of Pharmacy, Weifang Medical University, Baotong West Street, Weifang, Shandong Province, 261042, China; E-mail: wjy1980@wfmc.edu.cn, xiaoyawfmc@163.com
}

effective strategy for the treatment of AML. Differentiation therapy of acute promyelocytic leukemia (APL, a subtype of AML) with all-trans-retinoic acid (ATRA) has proven to be extremely successful in inducing clinical remission in APL patients. The tremendous success and clinical impact of this differentiation therapy changed the survival curve of patients with APL, which was once one of the worst prognosis subgroups in AML, and now its prognosis is the best, with an overall survival rate of $85 \%$ [8-9]. Some studies on multiple cell lines have shown that CDK2 has a new role in cellular differentiation, no matter what its role is in the cell cycle [10]. By inhibiting CDK2 and other cyclin dependent kinases CDK1/4/6, granulocyte differentiation can be induced between patients and AML 5 subtype clones. In the mechanism, CDK2 deficiency can reactivate the translation of differentiation thoroughfare, and the differentiation blocking-up function of CDK2 can be immediately realized by keeping the activity of Peroxirdoxin 2 . The protease inhibitor MG132 was used to detect whether the reduction of CDK was caused by degradation, and the study has shown that MG132 can eliminate the decline of CDK2 caused by ATRA, but has no effect on the decline of CDK1, CDK4 and CDK6 (Table 1). By using MG132 inhibitor, CDK2 has been found as a key protein for proteasome specific degradation. Inhibition of CDK2 by consumption or drugs can relieve the situation of human AML cell differentiation block. These data indicate a key target for differentiation therapy. In the normal cell cycle, the potency of CDK remained relatively stable [11]. Surprisingly, CDK2 was degraded by proteasome during granulocyte differentiation of AML cells. This degradation in CDK2 has been covered in other differentiation models [12-13]. To further demonstrate that CDK2 is a ubiquitination substrate, cycloheximide $(\mathrm{CHX})$ was used to stop the synthesis of 
Table 1: The effect of MG132 on CDK expression

\begin{tabular}{|c|c|c|c|c|c|c|c|c|}
\hline ATRA & $0 \mathrm{~h}$ & $24 \mathrm{~h}$ & $48 \mathrm{~h}$ & $72 \mathrm{~h}$ & $0 \mathrm{~h}$ & $24 \mathrm{~h}$ & $48 \mathrm{~h}$ & $72 \mathrm{~h}$ \\
\hline MG132 & - & - & - & - & + & + & + & + \\
\hline $\mathrm{CDK} 2$ & ש & - & - & - & 口 & 口 & 口 & 口 \\
\hline CDK1 & 口 & - & - & - & ש & - & - & - \\
\hline CDK4 & ש & - & - & - & ש & - & - & - \\
\hline CDK6 & ש & - & - & - & ש & - & - & - \\
\hline B-Actin & ש & D & D & a & ש & ש & 口 & 口 \\
\hline
\end{tabular}

new proteins. In the presence of $\mathrm{CHX}, \mathrm{CDK} 2$ is unstable, while MG132 blocks the turnover of CDK2 and further strengthens polyubiquitination of CDK2. And then an ubiquitin E3 joinase responsible for ubiquitination and degradation of CDK2 through $\mathrm{Y} 2 \mathrm{H}$ screening was searched [14]. Human CDK2 was used as a tool to screen potential CDK2 interacting proteins from $\mathrm{Y} 2 \mathrm{H}$ quarry library having open reading frame (ORF). There are 400 recognized ubiquitin ligases or their substrate binding subunits [15]. Internal ubiquitination experiments indicated that only klhl6 promoted the build-up of polyubiquitinated CDK2. Consequently, KLHL6 levels were regulated and the stability of CDK2 protein was determined.

The results indicated that klhl6 overexpression enhanced the degradation of endogenous CDK2 and exogenous wild-type (WT) CDK2, but not ubiquitin deficient CDK2 mutant (m-2r). On the contrary, klhl6 deletion extended the half-life period of endogenous CDK protein. These results show that klhl6 acts as an ubiquitin E3 ligase of CDK2 protein. All in all, the depletion of CDK2 relieves the differentiation retardant in both AML clones and primary specimens.

\subsection{Isocitrate Dehydrogenase (IDH1, IDH2)}

All three enzymes (IDH1, IDH2 and IDH3) belong to the IDH clan, which all catalyze the oxidative decarboxylation of isocitric acid to $\mathrm{CO}_{2}$ and aketoglutarate (AKG) [15]. In human cancers, mutations were found only in IDH1 and IDH2 [16-17]. IDH1 and $\mathrm{IDH} 2$ are $\mathrm{NADP}^{+}$-dependent enzymes and play a significant role in cell respiration and antioxidant stress [16-17]. In recent years, with the discovery of somatic cell mutations of arginine residues in IDH1-R132, IDH2-R140 and IDH2-R172, IDH1-R132, IDH2-R140 and IDH2-R172, the significance of IDH in malignant tumors has been increasingly recognized. These mutations can lead to the imbalance of cell maintenance, unsuitable proliferation, and ultimately lead to the tumor [18-21]. The abnormity caused by IDH1 and IDH2 mutations in tumors is not only related to the obstruction of normal cell activity, but also to the

(1) $\mathbf{a K G} \stackrel{\text { mutant IDH enzymes }}{\longrightarrow} 2 \mathbf{H G}^{\uparrow} \stackrel{\text { IDH inhibitors }}{\longrightarrow} 2 \mathrm{HG} \downarrow \longrightarrow$ Malignant cells differentiate normally

(2) Bcl-2 $\stackrel{\text { Bcl-2 inhibitors }}{\longrightarrow}$ disinhibition of $\mathrm{BAX} \longrightarrow$ release apoptotic factor cytochrome $\mathrm{c}$ Downstream apoptosis

(3) mutant IDH $\longrightarrow 2 \mathrm{HG} \longrightarrow$ inhibit the mitochondrial transport protein $\longrightarrow$ cell apoptosis 
abnormal enzymatic function of AKG to create D-2hydroxyglutaric acid (2HG) [22-25]. Further analysis of grown-up AML discovered not only IDH1-R132 but also mutant IDH2 enzymes, IDH2-R140 and IDH2-R172, which were confirmed in about $20 \%$ of AML sufferers [26-28]. Particularly approximately $6-16 \%$ of AML patients have IDH1 mutations; and approximately 8$19 \%$ have IDH2 mutations [27, 29, 30]. IDH mutation was often related to increased co-occurrence of NPM1 and FLT3-ITD [29, 31]. In AML, IDH2 mutations are more than IDH1 mutations, while IDH1 and IDH2 mutations rarely occur at the same time [32-33]. Like other epigenetic activity mutations, IDH1 and IDH2 mutations are often discovered in pernicious clonal evolution [34]. The positive role of IDH mutation in tumorigenesis has led to the development of small molecule targeted inhibitors for IDH. The catalyze sites of IDH1 and IDH2 were used as combining targets of small molecule inhibitors to cease the reduction of oncometabolite $2 \mathrm{HG}$ by AKG [35].

\subsection{Homeobox Genes (HoxA9)}

Recent studies have shown that HoxA9, a transcriptional factor with isogeny domain, is usually relieved in acute leukemia. In this study, two different types of leukemia cells HL-60 and MOLT- 3 were used to show the direct correlation between HoxA9 expression and leukemia progression. After treatment with all trans-retinoic acid or arsenic trioxide $\left(\mathrm{As}_{2} \mathrm{O}_{3}\right)$, the expression level of HOXA9 in leukemia cells has reduced. Down regulation of HoxA9 can destroy the multiplication of leukemia cells and promote the death of leukemia cells. HoxA9 silencing also strengthened the differentiation of leukemia cells. Internal studies indicated that down-regulation of HoxA9 likely interfere with tumor growth. Interestingly, HoxA9 silencing also results in changes in miRNA expression, which mediates the promotion of leukemia cell differentiation. Therefore, this work provides a promising and potential effective target for leukemia treatment, which indicates that HOXA9 may be an ideal candidate target for genetic therapy of acute myeloid leukemia. In this study, the key role of HoxA9 in the multiplication and differentiation of leukemia cells external and internal has been clarified. The regulation effect of HoxA9 is related to the clinical effect of all trans-retinoic acid and $\mathrm{As}_{2} \mathrm{O}_{3}$. On the other hand, HoxA9 can regulate the expression of miRNA and control the differentiation of leukemia cells. The imbalance of Hox gene clan is related to the occurrence of AML [36]. Hox family plays an important role in hematopoietic development [37]. The abnormal expression of HoxA is one of the principal factors in bone marrow transformation. HoxA9, one of the HoxA clan genes, was discovered to be highly correlated with the poor prognosis of AML [38-40]. The expression of HoxA9 in AML patients is higher than that in healthy contrasts [41], which may show that HoxA9 plays a direct role in deciding the prognosis of AML [42].

The role of HoxA9 in the multiplication, apoptosis and differentiation of leukemia cells ATRA or $\mathrm{As}_{2} \mathrm{O}_{3}$ can reduce the expression of HoxA9 in leukemia cells, which shows that the expression of HoxA9 is potentially related to the progression or grade malignancy of leukemia cells. HoxA9 silencing can reduce the multiplication and promote cell death of HL-60 or MOLT-3 cells. At the same time, HoxA9 silencing also put off the differentiation of leukemia which was regulated by some miRNA expression changes. More importantly, similar results have been obtained internally in xenotransplantation experiments. HoxA9 new targets play a significant role in the progress of leukemia, which is hopeful to provide a new direction for the treatment of leukemia. Statistical analysis showed that the expression level of HoxA9 was decreased by $68 \pm 6 \%$ and $79 \pm 7 \%$ in ATRA-or $\mathrm{As}_{2} \mathrm{O}_{3}$ treated HL-60 cells $(\mathrm{P}<0.1$, Table 2$)$. Similarly, the HoxA9 expression level was reduced by $79 \pm 6 \%$ and $83 \pm 7 \%$ in ATRA-or $\mathrm{As}_{2} \mathrm{O}_{3}$-treated MOLT-3 cells ( $\mathrm{P}<$ 0.1 , Table 2). All these data showed that HoxA9 likely functions as a target gene to ATRA or $\mathrm{As}_{2} \mathrm{O}_{3}$ treatment of leukemia cells.

Table 2: The expression level of HoxA9

\begin{tabular}{ccc}
\hline & ATRA & $\mathrm{As}_{2} \mathrm{O}_{3}$ \\
\hline HL-60 & $68 \pm 6 \% \downarrow$ & $79 \pm 7 \% \downarrow$ \\
MOLT-3 & $79 \pm 6 \% \downarrow$ & $83 \pm 7 \% \downarrow$ \\
\hline
\end{tabular}

\subsection{Dihy-Droorotate Dehydrogenase (DHODH)}

DHODH is an enzyme that catalyzes the oxidation of dihydroorotate (DHO) to orotate (ORO) during the de novo synthesis of pyrimidine in cells. Pyrimidine is essential for cell metabolism and cell growth. It is an important precursor of nucleotide, glycoprotein, phospholipid biosynthesis and nucleotide cycle [43]. Dysregulation and functional dependence of pyrimidine biosynthesis have been found in a variety of solid tumors [44]. As a key enzyme regulating this process, DHODH has been identified as a synthetic lethal target mutation of tumors carrying specific genes. In a recent preclinical findings of Sikes et al., it is suggested that $\mathrm{DHODH}$ is a metabolic regulator in the pyrimidine 
synthesis pathway and a new target for differentiation therapy of AML [45]. Inhibition of DHODH can effectively promote cell differentiation and has an antileukemia effect in vitro. This discovery opens up a new perspective for differentiation therapy of AML with complex and heterogeneous gene mutations. It aims to develop new, effective and optimized DHODH inhibitors for clinical application and to study the mechanism of AML differentiation mediated by $\mathrm{DHODH}$ inhibition. The effects of DHODH knockout on apoptosis and differentiation of AML cells were observed by crispr-cas 9 mediated gene knockout. By analyzing the RNA sequencing data of $173 \mathrm{AML}$ samples, they found that DHODH and MYC are the key regulators of myeloid cell proliferation and differentiation, and they are co-expressed in AML. Through virtual screening of 337 natural products based on structure, the research team determined that isobavatamone, a chalcone extracted from Psoralea corylifolia, is a potent and selective DHODH inhibitor. Isovachorone is a competitive inhibitor of coq0 and a noncompetitive inhibitor of dihydrolauric acid (DHODH) substrate. It binds to the docking site of "ubiquinone channel" of DHODH complex and interacts with and stabilizes DHODH structurally [46].

It should be noted that DHODH alone is not enough to eliminate leukemia and should be used in combination with standard chemotherapy drugs or targeted specific inhibitors. Considering the genetic complexity of AML, the combination of $\mathrm{DHODH}$ inhibitors and some drugs with non- overlapping mechanisms may solve specific aspects of the complex pathogenesis of AML and ultimately improve the prognosis of patients.

\subsection{ETS Family Pioneer Transcription Factor (PU.1)}

PU.1, a precursor transcription factor of the ETS family is required for bone marrow formation [47]. In APL, the PML-RARA oncoprotein binds PU.1 protein and inhibits its function [48]. Mutant NPM1c(the commonest genetic lesion found in $30 \%$ of AML cases) and AML1-ETO similarly bind and disable PU.1, and expression of PU.1 is also reduced by RUNX1 [49]. Therefore, although the SPI1/PU.1 gene mutation is not common in human AML [50], its decreased activity is a common feature of the disease. Therefore, the decrease of PU.1 leads to arrest of bone marrow differentiation, which leads to AML. PU.1 plays an important role in promoting normal myeloid differentiation and AML differentiation induced by ATRA or LSD1 inhibitors [51]. It is reported that exogenous expression of PU.1 induced differentiation of myeloid progenitor cells or AML cells increased in vitro [52], but the effect in vivo by endogenous PU. 1 is still unclear. To solve this problem, primary AML246 or AML410 cells entered the RAG1 cohort $^{-1}(\mathrm{~cd} 45.1)$ mice (immunocompromised to allow implantation) developed leukemia cells stably expressing aggressive GFP (green fluorescent protein) with splenomegaly and thrombocytopenia. Doxycycline (DOX), a tetracycline analog, inhibits GFP in AML cells, restores the expression of endogenous PU.1 protein, and rapidly normalizes spleen size and blood count in 11 of 12 mice examined. After 2 to 3 months of remission, most DOX treated mice relapsed GFP+ mature AML, DOX insensitive shRNA activation and PU.1 inhibition, indicating a strong anti-selection effect on PU.1 function.

Acute DOX treatment induced the differentiation of immunophenotype and morphology of AML in leukemia mice, including down-regulating the labeling kit of stem cells and progenitor cells, inducing mature labeled CD11b granulocytes with segmental nucleus similar to neutrophils, and AML410 producing various mature myeloid cell types. The flow of AML cells isolated from the bone marrow of multiple leukemia mice was sequenced by RNA SEQ, whether untreated (GFP ${ }^{\text {high }}$ ) or DOX for 2, 4, or 6 days. In vivo repair of PU.1 triggered the consistent whole myeloid differentiation signal in AML246 and AML410, and the neutrophil signal was determined by the analysis of the mononuclear Gene Ontology $\left(P<10^{-8}\right)$ Granulocyte development $\left(P<10^{-5}\right)$ as a first-class approach. Hence, in these 2 models of poor outcome AML, restoring PU. 1 triggers leukemia differentiation and induces remission in vivo.

Primary AML246 and AML410 cells grew rapidly in the medium. DOX induced PU.1 repair significantly reduced cell proliferation and survival in a week. DOX triggers AML246 to differentiate into neutrophil like cells in vitro, while AML410 produces a variety of mature cell types. Stable PU.1 knockout driven control AML is not sensitive to DOX. This study minimized heterogeneous cells by obtaining media from a single AML246. Similar to the parental AML246, the clone was highly proliferative, accounting for about $60 \%$ of the original cells. Single cell tracking and imaging showed that DOX treatment reduced GFP fluorescence within 24 hours, decreased proliferation and activity within 1 week, and PU.1 recovered to produce morphologically differentiated culture after 2 weeks. Single cell RNA $S E Q$, phagocytic function and superoxide production 
analysis showed that DOX treated AML246 cells did not mature into functional neutrophils. However, compared with untreated AML246 cells, cd11 $b^{\text {high }}$ doxtreated AML246 cells showed significant transcriptional aggregation at transcriptome level and single myeloid mature gene expression, which confirmed that the differentiation of AML246 cells after PU.1 repair was uniform. The researchers then used the switchability of RNAi to study whether the AML maturation triggered by PU.1 recovery can be reversed. Cd11 $b^{\text {high }}$ cells were cultured in DOX for 14 days (28 days) to maintain the expression of PU.1 and mature phenotype. In contrast, DOX was extracted from classified $\mathrm{cd} 11 \mathrm{~b}^{\text {high }}$ cells on the 14th day, GFP was induced within 24 hours, the expression of PU. 1 and CD11b was decreased, and primary culture was produced within 1 week or 2 weeks. By evaluating the clone formation ability of mature AML cells in methylcellulose, this study determined the frequency at which PU.1 inhibition can restore differentiated AML cells to proliferative primary cells. About $20 \%$ of untreated AML246 cells formed shock colonies after 10 days of plating, which was prevented by adding DOX to methylcellulose. Remarkably, the clonality of cd11 b ${ }^{\text {high }}$ (about 90\% neutrophil like) cells isolated from DOX culture for 14 days in methylcellulose without DOX was only 4 times less than that of untreated cells, and $5 \%$ of cells formed colonies. The colonies from differentiated cells had no difference in shape, but were smaller than those inoculated with untreated AML cells, which was consistent with the delayed re participation of proliferation after DOX withdrawal. Similar reversals were observed in the primary culture and an independent clone of AML246.

To verify the differentiation at the single cell level, single AML246 cells were isolated after DOX treatment at different stages. These cells gradually increased the co-expression of CD11b and FC receptor CD16/32 and reduced the survival rate [53]. Single cells were classified into porous plate liquid culture to evaluate their clonality. Increasing the initial DOX treatment time reduced the clonogenicity of AML246 after DOX withdrawal; however, at 6-12 days after DOX withdrawal, $15 \%-20 \%$ of single $\mathrm{CD} 11 \mathrm{~b}^{+} \mathrm{CD} 16 / 32^{+}$cells formed rapidly growing clones. The mutant AML246 cells showed blast-like and low cd11 b ${ }^{\text {low }}$ cd16/32 $2^{\text {low }}$, which led to leukemia and re-differentiation under DOX re-exposure. It was confirmed that the dedifferentiation of AML246 cells was not due to the loss of clone of DOX reaction. After 18 days of DOX withdrawal, only $5 \%$ of AML246 cells survived, and CD $11 b^{+}$CD $16 / 32^{+}$cells screened from these cultures failed to form colonies. In conclusion, these results confirm that DOX withdrawal can restore single differentiated AML246 cells to clonal and leukemic status, but also indicate a potential maturation threshold beyond which dedifferentiation can be ignored. Importantly, in all tests, continuous DOX therapy eliminated the clonogenicity of AML246. When transplanted into recipient mice, differentiated AML246 clone cells from 2-week DOX culture (bulk or CD11 $b^{\text {high }}$ classification) produced fully permeable $\mathrm{GFP}^{+}$leukemia cells with a latency similar to or slightly longer than untreated cells, even though they were similar to neutrophils or bone marrow cells, and there were no immature mother cells and (pro) bone marrow cells at the time of injection. Dox-treated recipients are still disease-free, which is consistent with the inhibition of tumor by PU.1. Therefore, the reversion of transcription and phenotypic differentiation of AML cells by PU.1 inhibition can restore the leukemic nature of $A M L$ cells. After a series of follow-up experiments, inhibition of PU.1 in differentiated AML derived cells restored them to an immature, clonal, leukemic state [54].

\subsection{Fms-Like Tyrosine Kinase (FLT3)}

The human FLT3 gene is located on chromosome 13q12 [55]. FLT3 belongs to type III receptor tyrosine kinase, and its family members include kit, FMS and PDGF receptors [56]. FLT3 consists of five immunoglobulin-like domains in the extracellular domain, a tyrosine kinase (TK) domain separated by a kinase insert, and a C-terminal domain in the intracellular domain. Human FLT3 has two forms: 158$160 \mathrm{kda}$ glycosylated form and 130-143kda nonglycosylated form [57-58]. Under normal circumstances, FLT3 is only expressed in $\mathrm{CD} 34^{+}$ hematopoietic stem/progenitor cells and plays an important role in the development of hematopoietic stem cells, dendritic cell progenitor cells, B-cell progenitor cells and natural killer cells [59]. The deletion of the FLT3 gene in mice resulted in the deficiency of B cell progenitor cells. Subsequent transplantation studies further revealed the defects of $T$ cells and myeloid cells [60]. In the colony forming test of human $\mathrm{CD}_{3} 4^{+}$bone marrow cells, the high expression of FLT3 produced colony forming unit granulocyte monocyte (CFU-GM) colony, while the low expression of FLT3 produced erythroid colony [61]. In the inactivated state, FLT3 existed as a monomer on the cell membrane. After stimulation with FLT3 ligand (FLT3L), FLT3 dimers and trans-phosphorylates exposed tyrosine residues [62], which leads to activation of multiple downstream signaling pathways [63-64]. 
In this process, a series of signal transduction and adaptor proteins are involved, including Janus kinase(JAK), signal transducer and activator of transcription(STAT), extracellular signal regulated kinase (ERK1/2), phosphatidylinositol 3 kinase (PI3K), SRC-homologous 2(ship), phospholipase $\mathrm{C} \gamma(\mathrm{PLC}-\mathrm{\gamma})$, $\mathrm{CBL}$, growth factor receptor binding protein 2(Grb2) SHC, SRC-homologous 2 tyrosine phosphoprotein (SHP-2). The activation of this signaling event leads to proliferation increasing, apoptosis inhibition and of differentiation induction [65-67].

Although the expression of FLT3 is limited to CD34 positive people in normal bone marrow, its abnormal expression can be seen in primary cells of AML, pre-BALL, T-cell-ALL, blast phase CML and CLL patients. It is also expressed in most pre-B ALL and AML cell lines [68]. FLT3 and FLT3L co-expressed in 36\% (40 of 110 cases), indicating that these cells have an autocrine signal. The overexpression of FLT3 cannot make $\mathrm{Ba} / \mathrm{F} 3$ cells produce independent cytokines, but the overexpression of FLT3 leads to leukemia in mice, suggesting that FLT3L signal transduction may be required for the leukemic effect of FLT3 overexpression. However, the functional gain mutant of FLT3 can make Ba/F3 cells independent of cytokines, which indicates that they have carcinogenic potential without ligand involvement [69].

In 1996, FLT3 activation mutation was found for the first time in acute myeloid leukemia [70]. They now represent the most common molecular abnormalities in AML, making FLT3 a good therapeutic target.

\section{SUMMARY AND PROSPECT}

AML is an aggressive malignant tumor and the most common type of adult leukemia. In this article, studies about new targets for differentiation of AML cells in recent years have been reviewed. These targets are in different stages of development, which lay the foundation for the treatment of AML and further study of anti-tumor drugs. The increasing understanding of AML progression stages along with technological advancements provides direction for development of newer anticancer drugs targeting the specific proteins. These will ultimately improve the cure outcome of AML with better prognosis.

\section{REFERENCES}

[1] Justin W, Stephen N. Recent advances in the understanding and treatment of acute myeloid leukemia[J]. F1000research 2018; 7: 1196-1210.

https://doi.org/10.12688/f1000research.14116.1
Tenen DG. Disruption of differentiation in human cancer: AML shows the way[J]. Nat Rev Cancer 2003; 3: 89-101. https://doi.org/10.1038/nrc989

[3] Lowenberg B, Downing JR, Burnett A. Medical progressacute myeloid leukemia[J]. New Engl J Med 1999; 341: 10511062.

https://doi.org/10.1056/NEJM199909303411407

[4] Angela, Walasek. The new perspectives of targeted therapy in acute myeloid leukemia[J]. Advances in Clinical \& Experimental Medicine 2019; 28(2): 271-276. https://doi.org/10.17219/acem/81610

[5] Chen Y, Pan Y, Guo Y, et al. Tyrosine kinase inhibitors targeting FLT3 in the treatmentof acute myeloid leukemia[J]. Stem Cell Investigation 2017; 4(6): 48. https://doi.org/10.21037/sci.2017.05.04

[6] Kayser S, Levis MJ. Advances in targeted therapy for acute myeloid leukaemia[J]. British Journal of Haematology 2018; 180: 484-500. https://doi.org/10.1111/bjh.15032

[7] Madan V, Koeffler HP. Differentiation therapy of myeloid leukemia: four decades of development[J]. Blood 2021; 106(1): 26-38.

https://doi.org/10.3324/haematol.2020.262121

[8] Nowak D, Stewart D, Koeffler HP. Differentiation therapy of leukemia: 3 decades of development[J]. Blood 2009; 113(16): 3655-3665 https://doi.org/10.1182/blood-2009-01-198911

[9] Petrie K, Zelent A, Waxman S. Differentiation therapy of acute myeloid leukemia: past,present and future[J]. Curr Opin Hematol 2009; 16(2): 84-91 https://doi.org/10.1097/MOH.0b013e3283257aee

[10] Ying MD, Shao XJ, Jing $\mathrm{H}$, et al. Ubiquitin-dependent degradation of CDK2 drives the therapeutic differentiation of AML by targeting PRDX2[J]. Blood 2018; 131(24): 26982711.

https://doi.org/10.1182/blood-2017-10-813139

[11] Zhang J, Li H, Zhou T, et al. Cdk5 levels oscillate during the neuronal cell cycle: Cdh1 ubiquitination triggers proteosome dependent degradation during S-phase[J]. J Biol Chem 2012; 287(31): 25985-25994 https://doi.org/10.1074/jbc.M112.343152

[12] Wang L, Zhou GB, Liu P, et al. Dissection of mechanisms of Chinese medicinal formula Realgar-Indigo naturalis as an effective treatment for promyelocytic leukemia[J]. Proc Natl Acad Sci USA 2008; 105(12): 4826-4831. https://doi.org/10.1073/pnas.0712365105

[13] Tikoo R, Casaccia-Bonnefil P, Chao MV, Koff A. Changes in cyclin-dependent kinase2 and p27kip1 accompany glial cell differentiation of central glia-4 cells[J]. J Biol Chem 1997; 272(1): 442-447.

https://doi.org/10.1074/jbc.272.1.442

[14] Fields S, Song O. A novel genetic system to detect proteinprotein interactions[J]. Nature 1989; 340(6230): 245-246. https://doi.org/10.1038/340245a0

[15] Liu Z, Chen P, Gao H, et al. Ubiquitylation of autophagy receptor Optineurin by HACE1 activates selective autophagy for tumor suppression[J]. Cancer Cell 2014; 26(1): 106-120. https://doi.org/10.1016/j.ccr.2014.05.015

[16] Yang H, Ye D, Guan KL, et al. IDH1 and IDH2 mutations in tumorigenesis: mechanistic insights and clinical perspectives[J]. Clin Cancer Res 2012; 18(20): 5562-5571. https://doi.org/10.1158/1078-0432.CCR-12-1773

[17] Reitman ZJ, Yan H. Isocitrate dehydrogenase 1 and 2 mutations in cancer: alterationsat a crossroads of cellular metabolism[J]. J Natl Cancer Inst 2010; 102(13): 932-941. https://doi.org/10.1093/jnci/djq187

[18] Fujii T, Khawaja MR, DiNardo CD, Atkins JT, Janku F. Targeting isocitrate dehydrogenase (IDH) in cancer[J]. Discov Med 2016; 21(117): 373-380. 
[19] Lu C, Ward PS, Kapoor GS, et al. Abdel-Wahab O,et al. IDH mutation impairs histone demethylation and results in a block to cell differentiation[J]. Nature 2012; 483(7390): 474-478. https://doi.org/10.1038/nature10860

[20] Yen KE, Bittinger MA, Su SM, et al. Cancer-associated IDH mutations: biomarker andtherapeutic opportunities[J]. Oncogene 2010; 29(49): 6409-6417. https://doi.org/10.1038/onc.2010.444

[21] Dang L, Jin S, Su SM. IDH mutations in glioma and acute myeloid leukemia[J]. Trends Mol Med 2010; 16(9): 387-397. https://doi.org/10.1016/j.molmed.2010.07.002

[22] Dang L, White DW, Gross S, et al. Cancer-associated IDH1 mutations produce 2-hydroxyglutarate[J]. Nature 2009; 462(7274): 739.

https://doi.org/10.1038/nature08617

[23] $\mathrm{Xu} \mathrm{W}$, Yang $\mathrm{H}$, Liu $\mathrm{Y}$, et al. Oncometabolite 2hydroxyglutarate is a competitive inhibitor of a-ketoglutaratedependent dioxygenases[J]. Cancer Cell 2011; 19(1): 17-30. https://doi.org/10.1016/i.ccr.2010.12.014

[24] Figueroa ME, Wahab OA, Lu C, et al. Leukemic IDH1 and IDH2 mutations result in a hypermethylation phenotype, disrupt TET2 function, and impair hematopoietic differentiation[J]. Cancer Cell 2010; 18(6): 553-567. https://doi.org/10.1016/j.ccr.2010.11.015

[25] Ward PS, Cross JR, Lu C, et al. Identification of additional IDH mutations associatedwith on cometabolite R(-)-2hydroxyglutarate production[J]. Oncogene 2012; 31(19): 2491-2498.

https://doi.org/10.1038/onc.2011.416

[26] Abbas S, Lugthart S, Kavelaars FG, et al. Acquired mutations in the genes encoding IDH1 and IDH2 both are recurrent aberrations in acute myeloid leukemia: prevalence and prognostic value[J]. Blood 2010; 116(12): 2122-2126.

https://doi.org/10.1182/blood-2009-11-250878

[27] Marcucci G, Maharry K, Wu YZ, et al. IDH1 and IDH2 gene mutations identify novel molecular subsets within de novo cytogenetically normal acute myeloid leukemia: a Cancer And Leukemia Group B Study[J]. J Clin Oncol 2010; 28(14): 2348-2355.

https://doi.org/10.1200/JCO.2009.27.3730

[28] Paschka P, Schlenk RF, Gaidzik VI, et al. IDH1 and IDH2 mutations are frequent genetic alterations in acute myeloid leukemia and confer adverse prognosis in cytogenetically normal acute myeloid leukemia with NPM1 mutation without FLT3 internal tandem duplication[J]. J Clin Oncol 2010; 28(22): 3636-3643.

https://doi.org/10.1200/JCO.2010.28.3762

[29] DiNardo CD, Ravandi F, Agresta S, et al. Characteristics, clinical outcome, and prognostic significance of IDH mutations in AML[J]. Am J Hematol 2015; 90(8): 732-73. https://doi.org/10.1002/ajh.24072

[30] Chou WC, Lei WC, Ko BS, et al. The prognostic impact and stability of isocitrate dehydrogenase 2 mutation in adult patients with acute myeloid leukemia[J]. Leukemia 2011; 25(2): 246-253.

https://doi.org/10.1038/leu.2010.267

[31] Medeiros BC, Fathi A T, DiNardo CD, et al. Isocitrate dehydrogenase mutations in myeloid malignancies[J]. Leukemia 2017; 31(2): 272-281.

https://doi.org/10.1038/leu.2016.275

[32] Stein EM. IDH2 inhibition in AML: finally progress?[J] Best Pract Res Clin Haematol 2015; 28(2-3): 112-115. https://doi.org/10.1016/j.beha.2015.10.016

[33] Platt MY, Fathi AT, Borger DR, et al. Detection of dual IDH1 and IDH2 mutations by targeted next-generation sequencing in acute myeloid leukemia and myelodysplastic syndromes[J]. J Molr Diagnostics 2015; 17(6): 661-668. https://doi.org/10.1016/j.jmoldx.2015.06.004
[34] Papaemmanuil E, Gerstung M, Bullinger L, et al. Genomic classification and prognosisin acute myeloid leukemia[J]. N Engl J Med 2016; 374(23): 2209-2221. https://doi.org/10.1056/NEJMoa1516192

[35] Wang F, Travins J, DeLaBarre B, et al. Targeted inhibition of mutant IDH2 in leukemia cells induces cellular differentiation[J]. Science 2013; 340(6132): 622-626. https://doi.org/10.1126/science.1234769

[36] Braekeleer ED, Douet-Guilbert N, Basinko A, et al. Hox gene dysregulation in acute myeloid leukemia[J]. Future Oncol 2014; 10: 475-495. https://doi.org/10.2217/fon.13.195

[37] Taniguchi Y. Hox transcription factors: modulators of cell-cell and cellextracellular matrix adhesion[J]. Biomed Res Int 2014; 2014: 1-12.

https://doi.org/10.1155/2014/591374

[38] Andreeff M, Ruvolo V, Gadgil S, et al. HOX expression patterns identify a common signature for favorable AML[J]. Leukemia 2008; 22: 2041-2047. https://doi.org/10.1038/leu.2008.198

[39] Collins $\mathrm{C}$, Wang J, Miao $\mathrm{H}$, et al. C/EBPalpha is an essential collaborator in Hoxa9/Meis1-mediated leukemogenesis[J]. Proc Natl Acad Sci USA 2014; 111: 9899-9904. https://doi.org/10.1073/pnas.1402238111

[40] Tholouli E, MacDermott S, Hoyland J, et al. Quantitative multiplex quantum dot in-situ hybridisation basedgene expression profiling in tissue microarrays identifies prognostic genes in acute myeloid leukaemia[J]. Biochem Biophys Res Commun 2012; 425: 333-339.

https://doi.org/10.1016/j.bbrc.2012.07.092

[41] Figueroa ME, Lugthart $\mathrm{S}$, Li $\mathrm{Y}$, et al. DNA methylation signatures identify biologically distinct subtypes in acute myeloidleukemia[J]. Cancer Cell 2010; 17: 13-27. https://doi.org/10.1016/j.ccr.2009.11.020

[42] Karakas T, Maurer U, Weidmann E, et al. High expression of bcl-2 mRNA as a determinant of poor prognosis in acute myeloid leukemia[J]. Ann Oncol 1998; 9: 159-165. 43.

https://doi.org/10.1023/A:1008255511404

[43] Levine RL, Hoogenraad NJ, Kretchmer N. A review: biological and clinical aspects of pyrimidine metabolism[J] Pediatr Res 1974; 8(7): 724-734. https://doi.org/10.1203/00006450-197407000-00008

[44] DeBerardinis RJ, Lum JJ, Hatzivassiliou G, et al. The biology of cancer:metabolic reprogramming fuels cell growth and proliferation[J]. Cell Metab 2008; 7: 11-20. https://doi.org/10.1016/j.cmet.2007.10.002

[45] Sykes DB, Kfoury YS, Mercier FE, et al. Inhibition of dihydroorotate dehydrogenaseovercomes differentiation blockade in acute myeloid leukemia[J]. Cell 2016; 167(1): 171-186. https://doi.org/10.1016/j.cell.2016.08.057

[46] Zeng Z, Konopleva M. Targeting dihydroorotate dehydrogenase in acute myeloid leukemia[J]. Haematologica 2018; 103(9): 1415-1417.

https://doi.org/10.3324/haematol.2018.197806

[47] Carotta S, Wu L, Nutt SL. Surprising new roles for PU.1 in the adaptive immune response[J]. Immunol. Rev 2010; 238: 63-75.

https://doi.org/10.1111/j.1600-065X.2010.00955.x

[48] Seshire A, Rößiger T., Frech M., et al. Direct interaction of PU.1 with oncogenic transcription factors reduces its serine phosphorylation and promoter binding[J]. Leukemia 2012; 26: 1338-1347. https://doi.org/10.1038/leu.2011.331

[49] Gu X, Ebrahem Q, Mahfouz RZ, et al. Leukemogenic nucleophosmin mutation disrupts the transcription factor hub that regulates granulomonocyticfates[J]. J Clin Invest 2018; 128: $4260-4279$.

https://doi.org/10.1172/JCl97117 
[50] Ley TJ, Miller C, Ding L, et al. Cancer Genome Atlas Research Network. Genomic and epigenomic landscapes of adult de novo acute myeloid leukemia[J]. N Engl J Med 2013; 368: 2059-2074.

\section{https://doi.org/10.1056/NEJMoa1301689}

[51] Cusan M, Cai SF, Mohammad HP, et al. LSD1 inhibition exerts its antileukemiceffect by recommissioning PU.1-and C/EBPa-dependent enhancers in AML[J]. Blood 2018; 131: 1730-1742.

https://doi.org/10.1182/blood-2017-09-807024

[52] Mueller BU, Pabs T, Fos J, et al. ATRA resolves the differentiation block in $t(15 ; 17)$ acute myeloid leukemia by restoring PU.1 expression[J]. Blood 2006; 107: 3330-3338. https://doi.org/10.1182/blood-2005-07-3068

[53] Evrard M, Kwok IWH, Chong SZ, et al. Development alanalysis of bone marrow neutrophils reveals populations specialized in expansion, trafficking, and effector functions[J]. Immunity 2018; 48: 364-379.

https://doi.org/10.1016/j.immuni.2018.02.002

[54] McKenzie MD, Margherita G, Ethan PO, et al. Interconversion between Tumorigenic and Differentiated States in Acute Myeloid Leukemia[J]. Cell Stem Cell 2019; 25(2): 258-272.

https://doi.org/10.1016/j.stem.2019.07.001

[55] Rosnet O, Stephenson D, Mattei MG, et al. Close physical linkage of the FLT1 and FLT3 genes on chromosome 13 in man and chromosome 5 in mouse[J]. Oncogene 1993; 8:173-179.

[56] Agnes F, Shamoon B, Dina C, et al. Genomic structure of the downstream part of the human FL T3 gene: exon/intron structure conservation among genes encoding receptor tyrosine kinases (RTK) of subclass III[J]. Gene 1994; 145: 283-288. https://doi.org/10.1016/0378-1119(94)90021-3

[57] Lyman SD, James L, Zappone J, et al. Characterization of the protein encoded by the flt3 (flk2) receptor-like tyrosine kinase gene[J]. Oncogene 1993; 8: 815-822.

[58] Carow CE, Levenstein M, Kaufmann SH, et al. Expression of the hematopoietic growth factor receptor FLT3 (STK-1/Flk2) in human leukemias[J]. Blood 1996; 87: 1089-1096. https://doi.org/10.1182/blood.V87.3.1089.bloodjournal873108 $\underline{9}$

[59] Rosnet O, Schiff C, Pebusque MJ, et al. Human FLT3/FLK2 gene: cDNA cloning and expression in hematopoietic cells[J]. Blood 1993; 82: 1110-1119. https://doi.org/10.1182/blood.V82.4.1110.bloodjournal824111 $\underline{0}$
[60] Mackarehtschian K, Hardin JD, Moore KA, et al. Targeted disruption of the flk2/flt3 gene leads to deficiencies in primitive hematopoietic progenitors[J]. Immunity 1995; 3 : 147-161.

https://doi.org/10.1016/1074-7613(95)90167-1

[61] Gotze KS, Ramirez M, Tabor K, et al. Flt3high and Flt3low CD34+ progenitor cells isolated from human bone marrow are functionally distinct[J]. Blood 1998; 91: 1947-1958. https://doi.org/10.1182/blood.V91.6.1947.1947 $1947 \quad 1958$

[62] Lyman SD. Biology of flt3 ligand and receptor[J]. Int J Hematol 1995; 62: 63-73.

[63] Rosnet $\mathrm{O}$, Bühring $\mathrm{HJ}$, DeLapeyrière $\mathrm{O}$, et al. Expression and signal transduction of the FLT3 tyrosine kinase receptor[J]. Acta Haematol 1996; 95: 218-223. https://doi.org/10.1159/000203881

[64] Lavagna-Sevenier C, Marchetto S, Birnbaum D, et al. FLT3 signaling in hematopoietic cells involves $\mathrm{CBL}, \mathrm{SHC}$ and an unknown P115 as prominent tyrosine-phosphorylated substrates[J]. Leukemia 1998; 12: 301-310. https://doi.org/10.1038/sj.leu.2400921

[65] Cook AM, Li L, Ho Y, et al. Role of altered growth factor receptor-mediated JAK2 signaling in growth and maintenance of human acute myeloid leukemia stem cells[J]. Blood 2014; 123: 2826-2837. https://doi.org/10.1182/blood-2013-05-505735

[66] Zhang S, Broxmeyer HE. p85 subunit of PI3 kinase does not bind to human Flt3 receptor, but associates with SHP2, SHIP, and a tyrosine-phosphorylated 100-kDa protein In Flt3 ligand-stimulated hematopoietic cells[J]. Biochem Biophys Res Commun 1999; 254: 440-445. https://doi.org/10.1006/bbrc.1998.9959

[67] Zhang SL, Mantel C, Broxmeyer HE. Flt3 signaling involves tyrosyl-phosphorylation of SHP-2 and SHIP and their association with Grb2 and Shc in Baf3/FIt3 cells[J]. J Leukoc Biol 1999; 65: 372-380.

https://doi.org/10.1002/jlb.65.3.372

[68] Meierhoff G, Dehmel U, Gruss HJ, et al. Expression of FLT3 receptor and FLT3-ligand in human leukemia-lymphoma cell lines[J]. Leukemia 1995; 9: 1368-1372.

[69] Hayakawa F, Towatari M, Kiyoi $\mathrm{H}$, et al. Tandem-duplicated Flt3 constitutively activates STAT5 and MAP kinase and introduces autonomous cell growth in IL-3-dependent cell lines[J]. Oncogene 2000; 19: 624-631. https://doi.org/10.1038/sj.onc.1203354

[70] Nakao M, Yokota S, Iwai T, et al. Internal tandem duplication of the flt3 gene found in acute myeloid leukemia[J]. Leukemia 1996; 10(12): 1911-1918.

Received on 03-12-2020

Accepted on $25-12-2020$

Published on 30-12-2020

\section{DOI: https://doi.org/10.30683/1929-2279.2020.09.10}

(C) 2020 Yao et al.; Licensee Neoplasia Research.

This is an open access article licensed under the terms of the Creative Commons Attribution Non-Commercial License (http://creativecommons.org/licenses/by-nc/3.0/) which permits unrestricted, non-commercial use, distribution and reproduction in any medium, provided the work is properly cited. 